\title{
Educational needs of dental trainers
}

\author{
A. J. Stewart ${ }^{1}$
}

The development of a curriculum for trainers in dental primary care, and its use in an assessment of their educational needs, was described in a previous paper1. This paper describes work in progress, which seeks to address the key issues raised by the earlier work.

"It had always
been
intended that
trainers
should master
the core
curriculum
before
proceeding
with further
development."

${ }^{1}$ Alexander J. Stewart, National Adviser for Trainer Development and General Dental Practitioner, Turriff, Scotland.

Correspondence: 6 High Street, Turriff, Aberdeenshire AB53 4DS.

\section{Preparation of New Trainers}

The trainers who worked on the curriculum ranked the outcomes for trainers in three categories: (a) essential core skills required by all trainers, (b) areas for natural progression and (c) optional additional skills for experienced trainers. The most striking feature of the curriculum they produced was the large proportion of outcomes regarded as the essential core. It was concluded that 'if the core outcomes are essential skills for all trainers, there is a strong case for a more extended preparation for new trainers.'

A series of eight one-day courses, linked by coursework, was required to cover the core curriculum. In addition, participants keep a portfolio and practice training techniques in the workplace, thereby modelling the elements of blended learning experienced by Vocational Dental Practitioners (VDPs) in their training year. An additional two-day residential block was planned as an assessment of participants' development on the course. The assessment takes the form of a presentation of evidence comprising an audit report, presentation of a training portfolio, videoed training episodes, live roleplays of training events, demonstration of skills teaching and a poster presentation. This process offers a mechanism for accreditation of all trainers.

A database of trainers' learning needs will allow existing trainers to be directed to training modules they may require before undertaking the accreditation process. By this means it is intended that all Scottish trainers will achieve accreditation of competence as a trainer, assessed against minimum assured standards defined by the trainer curriculum. A standard assessment is used for accreditation of all trainers.

A pilot of the extended preparation process was started in 2002 to prepare trainers who intended to start training in 2003. Out of 14 prospective trainers were recruited to the course, 13 completed the course satisfactorily. The participants gave con- structive feedback, and it was decided that with some modifications, the extended process should become the standard preparation for all Scottish trainers. To implement this policy without interrupting the flow of new trainers into Vocational Training (VT), new applicants in January 2003 started the Scottish Trainer Training (START) modular course in February 2003. This group will begin training a VDP at the midway point of their START course, and will complete it in December 2003. Practitioners who intend to begin training in August 2004 commenced the START course in August 2003, and the summer starting model will in future be the norm. Table 1 shows an outline of the START course. Programmes for individual modules will include periods for reviewing participants' portfolios and giving feedback and other course related discussions, and all participants will complete the European Computer Driving License (ECDL).

The individual course modules are evaluated using both pre- and post- course questionnaires and a number of other procedures have been put in place in an attempt to measure change in participants and to evaluate the impact of the course. The results of this evaluation will be reported in due course.

\section{Assessment of trainers' educational needs}

The assessment of trainers' needs described previously used a questionnaire based on the curriculum. Analysis of the completed questionnaires suggested that the self reported data was not reliable and that educational appraisal of trainers might produce a more reliable needs assessment. However the curriculum covers a large number of individual outcomes, both core and additional, which would be almost impossible to cover in the appraisal setting and tends to generate a wide and unmanageable array of needs, as did the questionnaire approach. There is little point in discovering needs unless they can be addressed. The decision to adopt the two- 


\section{Table 1}

\begin{tabular}{|c|c|c|}
\hline Date & Module & Title \\
\hline August 21st \& 22nd 2003 & Module 1 \& 2 & $\begin{array}{l}\text { The VT Year, The Role of the Trainer. Trainer and VDP record books. Preparation of practice, staff and } \\
\text { trainer for training. What makes a good tutorial? Feedback skills. Objective setting and Learning plans. } \\
\text { Vocational training in Scotland accreditation (VISA) \& the Matching process. (For module } 2 \text { participants } \\
\text { will prepare objectives and learning plan for a member of the practice team) }\end{array}$ \\
\hline September 19th 2003 & Module 3 & $\begin{array}{l}\text { Training the Dentists Course: Introduction to ECDL (for module participants will make a video of a } \\
\text { training event in practice) }\end{array}$ \\
\hline October 31st 2003 & Module 4 & $\begin{array}{l}\text { Introduction to Audit: Clinical Skills Instruction (for module } 9 \text { participants will conduct an audit for } \\
\text { presentation) }\end{array}$ \\
\hline November 28th 2003 & Module 5 & $\begin{array}{l}\text { Video analysis and Feedback - Presentation Skills, Critical Reading (for module } 10 \text { participants will } \\
\text { make } a \text { further video of a training event) }\end{array}$ \\
\hline January 16th 2004 & Module 6 & Appraisal Skills: Audit clinic \\
\hline February 6th 2004 & Module 7 & Employment Law: Interviewing and being interviewed \\
\hline May 8th 2004 & Module 8 & The Scottish Assessment System: PPT Session/posters \\
\hline June 9th \& 10 th 2004 & Module 9 \& 109 \& 10 & $\begin{array}{l}\text { Final Two-day Module. Evidence for certification (comprising presentation of a completed training } \\
\text { portfolio, poster presentation of an audit project, videoed training episodes, live role plays of training } \\
\text { events and demonstration of skills teaching.) }\end{array}$ \\
\hline
\end{tabular}

The individual course modules are evaluated using both pre- and post- course questionnaires and a number of other procedures have been put in place in an attempt to measure change in participants and to evaluate the impact of the course. The results of this evaluation will be reported in due course.

\section{Key Points:}

- A curriculum for dental trainers indicated a need for improved preparation for new trainers

- An extended preparation process was designed and piloted

- Participant feedback on the preparation process was positive and constructive

- The extended preparatory process is now the standard route into training for all Scottish trainers

- The assessment module of the preparation process can be applied as an accreditation system for all trainers

- All Scottish trainers will be accredited

- A revised appraisal process has been developed to assess trainers' educational needs

- A simplified database of trainers' needs is being constructed as appraisals proceed.
Acknowledgements: The author would like to thank Dr J S Rennie for his continuing support, $\mathrm{Mr} \mathrm{P}$ McKinlay and Mrs J Ross for their invaluable assistance in developing and delivering the START course and Professor C Bulstrode and DrV Hunt whose 'Training the Dentists' course is used as the third module of START. Scottish Trainer Development is funded by NHS Education Scotland.

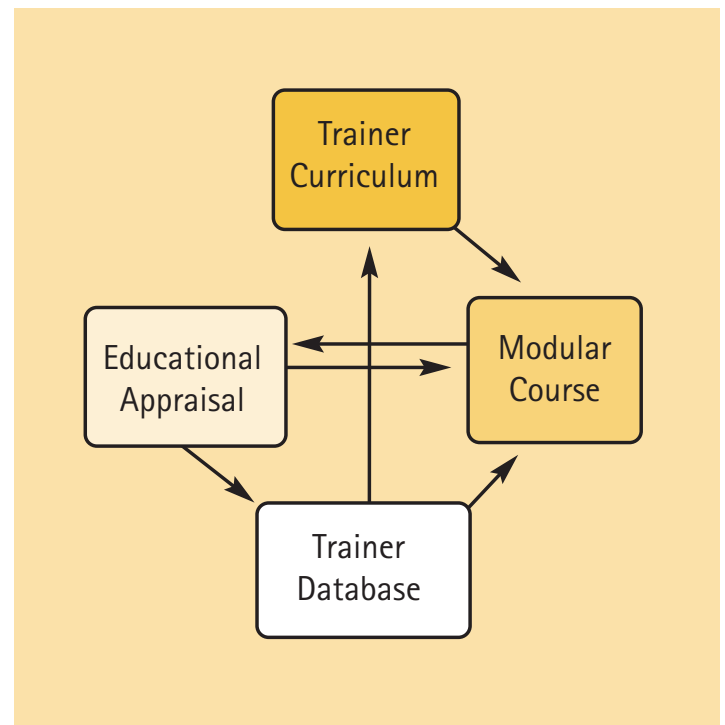

Figure 1. The structure that links the curriculum to the practical delivery of courses and targeted to meet the needs of individual trainers. day presentation of evidence, covering the core outcomes, as an accreditation process for all trainers, has offered a solution to these problems.

It had always been intended that trainers should master the core curriculum before proceeding with further development. The two-day assessment module serves as a test of this criterion. The assessment is based on the content of the eight course modules, which are in turn based on the core curriculum outcomes. If appraisal explores and reports trainers' needs under headings that match the content of the course modules then it covers the core by default, and simultaneously identifies needs that can be addressed by the courses which system matches the modular course and informs a matching database. The database is used to direct trainers to appropriate course modules and to feed back to the curriculum. Figure 1 shows the relationship between the elements described.

\section{Future Developments}

It will be necessary to conduct a robust evaluation of the START course and feedback is being collected at various points before, during and after the courses from participants, facilitators and others who interact during the training situations. A strength of having based the courses on an outcome-based curriculum is that the intended outcomes of the process are clearly defined and therefore measurable. Courses can be modified in the light of evaluation. Impact studies will continue for some time and will be reported in due course. In the longer term, once all trainers have achieved accreditation, a structured approach to the non-core outcomes of the curriculum will be devised as further development for those trainers who choose to remain in VT for prolonged periods.

1 Stewart A J, Clarkson J. An assessment of the educational needs of dental trainers, based on an outcome-based curriculum. Br Dent (Suppl) 2002; Education and training supplement: 25-28. 